\title{
PNGVL4a-Sig/E7(detox)/HSP70 DNA Vaccine
}

National Cancer Institute

\section{Source}

National Cancer Institute. pNGVL4a-Sig/E7(detox)/HSP70 DNA Vaccine. NCI Thesaurus.

Code C48418.

An antigen-specific DNA cancer vaccine consisting of the coding sequences of a signal peptide (pNGVL4a-Sig), a detox form of the human papillomavirus type 16 (HPV-16) antigen E7, and the heat shock protein 70 (HSP70). Upon administration, this vaccine may generate potent cytotoxic CD8(+) T-cell responses against E7-expressing tumor cells, resulting in tumor cell death. 